\title{
Optimizing water supply headworks operating rules under stochastic inputs: Assessment of genetic algorithm performance
}

\author{
Lijie Cui and George Kuczera \\ School of Engineering, University of Newcastle, Callaghan, New South Wales, Australia \\ Received 22 July 2004; revised 5 December 2004; accepted 16 February 2005; published 18 May 2005.
}

[1] Realistic optimization of the operation of urban water supply headworks systems requires that the issues of system complexity and stochasticity be addressed. A promising way of achieving this is to couple probabilistic search methods such as genetic algorithms (GAs) with Monte Carlo simulation models. However, the objective function surface, characteristic of this genre of problem, exhibits piecewise flat regions separated by steep slopes. The size of these flat regions is affected by the frequency of droughts sampled in the Monte Carlo simulation. Although an earlier study proposed a GA variant that appears to robustly negotiate such objective function surfaces, the assessment was limited to a simple one-reservoir system. There remains therefore a legitimate concern that for more complex systems the GA may converge prematurely producing decisions of little practical value. This study assesses the ability of the GA to optimize key operating rules for a complex urban headworks system with nine reservoirs and interbasin transfers subject to a highly variable climate. Eight decisions affecting restriction rules, pump marks, and contingent desalination were optimized using an objective function that minimized expected annual costs. It is shown that the GA produced results that are judged consistent with the strategy that minimizes total expected costs. In addition, the sensitivity of the GA results to the length of the Monte Carlo simulation was investigated.

Citation: Cui, L., and G. Kuczera (2005), Optimizing water supply headworks operating rules under stochastic inputs: Assessment of genetic algorithm performance, Water Resour. Res., 41, W05016, doi:10.1029/2004WR003517.

\section{Introduction}

[2] Water supply headworks systems consist of a network of interconnected surface and subsurface reservoirs that harvest and store water which is then distributed to consumption zones. Such systems are usually characterized by their complexity and stochastic inputs. Typically they have multiple users, possibly with different objectives and risk tolerances, and also multiple sources with different levels of quality. The objectives of operating a typical water supply headworks system usually reflect the need to achieve an acceptable level of reliability, to minimize operating costs and in the case of growing demand to defer the time to the next augmentation. The decision variables affecting the operation of headworks systems may include target levels for storages, target pumping levels and rules for the introduction of restrictions. Water restrictions of varying severity are imposed at times when it is deemed that the probability of failure (i.e., the system being unable to meet demand) is beyond a critical level. Major urban water supply authorities have policies indicating when water restrictions of varying severity will be applied. Typically these rules are based on experience, supplemented in some cases by the use of computer simulation models [Dandy, 1987].

[3] In the last two decades, major advances in simulation technology have heralded the advent of generalized models,

Copyright 2005 by the American Geophysical Union. 0043-1397/05/2004WR003517\$09.00 which can be readily applied to a diverse range of complex systems. They can be used to simulate the behavior of the system in response to hydroclimatic inputs (streamflow, rainfall, etc.), consumptive requirements (urban, industrial and irrigation) and other environmental requirements given an infrastructure and an operating policy. In Australia, several models have gained considerable industry acceptance (e.g., REALM [Kuczera and Diment, 1987], IQQM [Department of Water Resources, 1995], HOMA [Crawley and Dandy, 1993], and WATHNET [Kuczera, 1997]). Because of the ease with which infrastructure options and operating policy options can be changed, these models have enabled comprehensive "what if" assessments.

[4] When coupled with probability models of hydroclimatic inputs and consumptive requirements, generalized models can perform Monte Carlo simulation to produce a risk analysis of the consequences of droughts and other environmental stresses. It is widely accepted that simulation models using hydroclimatic inputs generated by Monte Carlo methods provide the most realistic models of future water resource system behavior. Unfortunately, such models offer limited scope for optimizing system performance, typically requiring a trial-and-error approach.

[5] One way to avoid trial and error is to employ probabilistic search methods to identify near-optimal operating rules. They can be readily coupled to a generalized simulation model and thus can accommodate complexity as well as stochastic inputs. The genetic algorithm (GA) is one such promising method and has been widely used in hydrology 
and water resources [e.g., Goldberg, 1989; Wang, 1991; Wardlaw and Sharif, 1999]. However, to the authors' knowledge, there exist no applications involving the optimization of complex headworks systems subject to stochastic inputs.

[6] Perhaps the main deterrent to such studies is the massive computational burden [Cui and Kuczera, 2003]. Simulation of complex systems using Monte Carlo methods usually involves a large number of hydroclimate replicates to ensure accurate estimation of drought-related performance. As a result, computational burdens can be very substantial. To appreciate the significance, it is noted that the GA typically requires thousands of objective function evaluations to achieve a near optimal solution. As an example, we consider the headworks system for Sydney, Australia, a nine-reservoir system serving multiple demand zones. A 1000-replicate simulation for the Sydney system takes about $400 \mathrm{CPU}$ seconds on a $750 \mathrm{MHz}$ Pentium III processor. Therefore an optimization search involving 2000 objective function evaluations would require a total $\mathrm{CPU}$ time of about 222 hours! Clearly, such CPU times severely limit the practical value of optimizing complex systems subject to stochastic inputs.

[7] Cui [2004] demonstrated that use of GAs in a parallel computing cluster could make computational turnaround times practically feasible. It was shown that the parallel GA was virtually $100 \%$ efficient using a parallel virtual machine cluster, meaning doubling the number of processors resulted in an almost halving of computational turnaround time regardless of the number of processors.

[8] Although the use of parallel GA offers the prospect of practical optimization the ability of the GA to yield nearoptimal solutions remains to be established. Cui and Kuczera [2003] demonstrated that the objective function surface, characteristic of this genre of problem, exhibits piecewise flat regions, possibly extensive, separated by steep slopes. The size of these flat regions is affected by the frequency of droughts, which stress the system, which in turn is affected by the number of replicates used in the Monte Carlo simulation. Although Cui and Kuczera [2003] proposed a GA variant that appears to robustly negotiate objective function surfaces with extensive flat regions, their assessment was limited to a simple one-reservoir system. There remains therefore a legitimate concern that for more complex systems the GA may converge prematurely producing decisions of little practical value.

[9] The objective of this study is to assess the ability of the parallel GA to optimize key operating rules of a complex urban headworks system. This is accomplished by evaluating in some detail the consistency and soundness of rules identified by the parallel GA for a real urban headworks system with a complex network of reservoirs forced by a climate which by world standards is highly variable (i.e., annual coefficient of variation for streamflow is approximately 1). The chosen system is the headworks system serving Sydney, Australia.

[10] This paper is organized as follows: The Sydney headworks system and its operation are described after which an overview of the WATHNET generalized simulation model is presented. The optimization problem is then formulated and the optimization model is outlined. Finally the results of the GA optimization for different population scenarios and different replicate lengths are presented and critically analyzed.

\section{Sydney Headworks System}

[11] The case study considers the Sydney water supply headworks system, which presently serves a population of over four million people. Average annual consumption in 2000 is assumed to be about $571000 \mathrm{ML}$ and is expected to grow to about 725000 ML by 2040 .

[12] The main purpose of the study is to evaluate the ability of the GA to yield near-optimal solutions. Some modifications to the Sydney headworks system and operation were deliberately introduced to better pursue this objective. Consequently, the results reported herein should not be construed as being applicable to the actual Sydney system.

\subsection{Description of the Headworks System}

[13] A schematic of the Sydney water headworks system is presented in Figure 1; the dashed arcs represent streams, while the solid arcs represent conduits. Cross-hatched nodes represent reservoirs, while nodes labeled with " $\mathrm{D}$ " represent demand.

[14] The headworks system serves two principal demand zones labeled as Sydney and Illawarra in Figure 1. It is assumed that $90 \%$ of the population resides in the Sydney zone with the remaining $10 \%$ residing in the Illawarra zone. Each of these zones has three demand categories: indoor domestic, outdoor domestic and commercial. This distinction is made because restrictions are typically targeted at outdoor domestic use and the economic implications of restrictions on each category are quite different.

[15] The water supply is drawn from four catchments: Upper Nepean, Warragamba, Shoalhaven and Woronora. Warragamba reservoir accounts for approximately $80 \%$ of the total system storage and receives $74 \%$ of the average annual inflow (excluding the Shoalhaven River). It delivers water to the Sydney zone by gravity to Prospect reservoir through pipelines with a capacity of $2600 \mathrm{ML} /$ day. Prospect reservoir is the major distribution reservoir in the system.

[16] Fours reservoirs regulate the Upper Nepean catchment: Cataract, Cordeaux, Avon and Nepean. The latter three can release water to the Sydney zone through natural river channels to a diversion weir at Pheasants Nest from where it is diverted by tunnel to Broughtons Pass weir and hence to Prospect reservoir. The transfer capacity of this system is $680 \mathrm{ML} /$ day. Water from Avon reservoir is mainly used to supply the Illawarra zone.

[17] At Lake Yarrunga on the Shoalhaven River, water is lifted $612 \mathrm{~m}$ to Fitzroy Falls reservoir using two pumping stations. Water is then transferred to Wingecarribee reservoir by canals and a pumping station, where it is stored and distributed either to Nepean or Warragamba reservoirs.

[18] One of the changes to the actual Sydney system was the addition of contingent desalination plant (node 34 in Figure 1). If the storage in Warragamba falls below a trigger level, construction of the desalination plant commences.

\subsection{Simulation of the Sydney Headworks System}

[19] WATHNET [Kuczera, 1997] is used to perform the headworks simulation in this case study. It is an example of a generalized simulation model that uses mathematical programming to reduce the need for explicit rules to make 


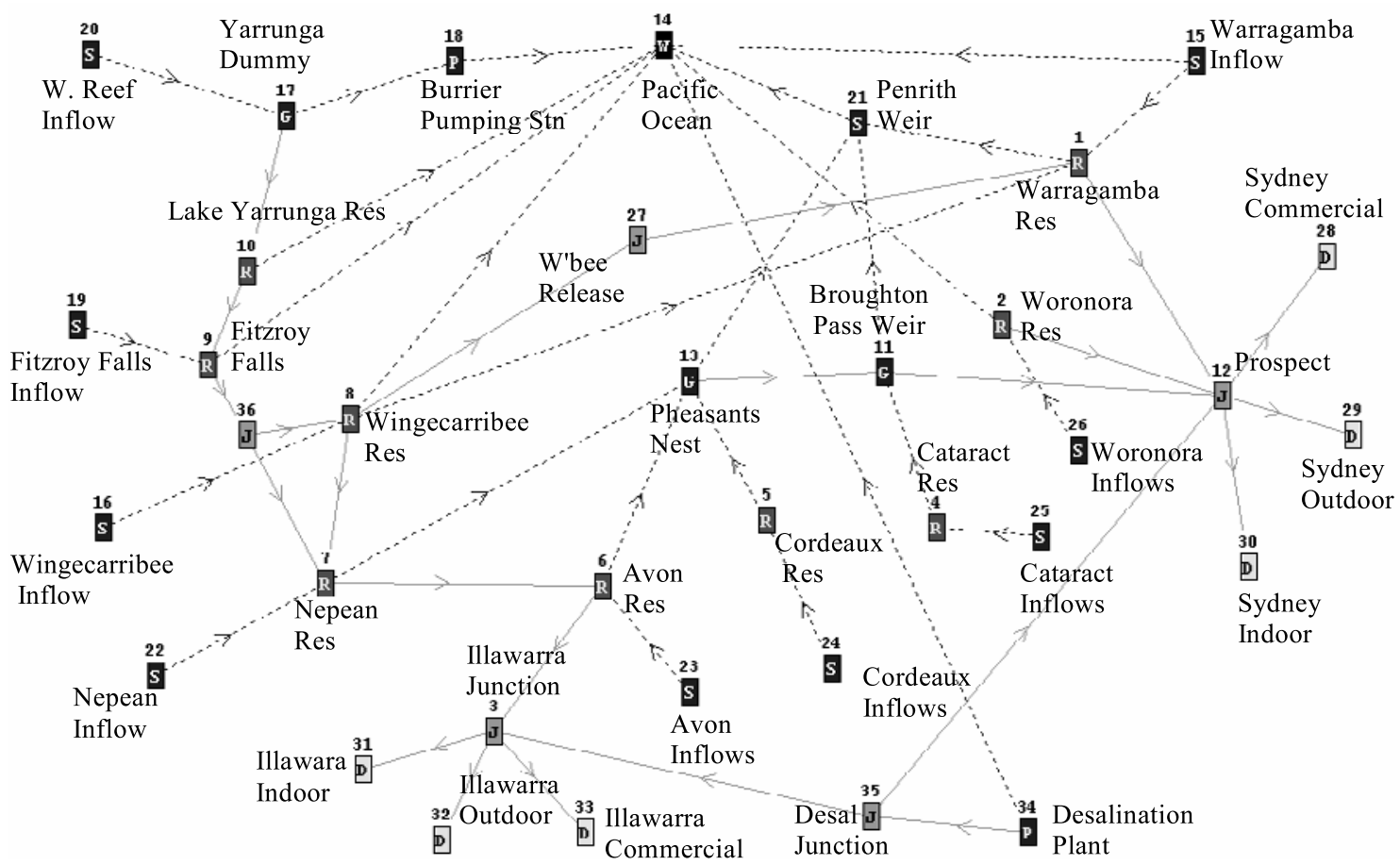

Figure 1. WATHNET schematic of Sydney headworks system. See color version of this figure in the HTML.

water assignments. WATHNET uses information about the current state of the system as well as forecasts of streamflow and demand to formulate a network linear program (NetLP), which, in its default mode, allocates water in accordance with the following hierarchy of objectives: (1) satisfy demand at all demand zones (if there is insufficient water in the system, or if there are transfer limitations, rationing will occur), (2) satisfy all in-stream flow requirements, (3) ensure that reservoirs are at their end-of-season target volumes, (4) minimize delivery costs, and (5) avoid unnecessary spill from the system. WATHNET consists of four program modules: (1) EDNET is used to define and edit the headworks schematic. (2) WATSTRM is a utility to stochastically generate hydroclimate data and manipulate large files. (3) SIMNET formulates the NetLP, performs multireplicate simulation, and saves results. (4) WATOUT is an interactive browsing facility used to graphically study the contents of the SIMNET output file.

\subsection{Operating Policy}

[20] The operating policy consists of the following sets of rules: reservoir drawdown curves; restriction trigger levels and pump marks.

[21] The drawdown curves determine the target volume for each reservoir for a given total volume of water. They have been formulated to minimize spill from the system [Snowy Mountains Engineering Corporation, 1996]. These curves have been implemented in WATHNET by subdividing storage into different zones and assigning gains (negative penalties), which guide the NetLP to, where possible, meets the conditional target volumes.

[22] The restriction policy defines the severity of demand restrictions and the storage trigger volumes at which the restrictions come into effect. It is primarily targeted at restricting outdoor domestic water use. The policy has four levels defined as level(j), $\mathrm{j}=1,4$ where level(j) is the percentage of storage capacity that triggers restrictions at the jth level; refer to the Cui [2004] for further details.

[23] During prolonged periods of less-than-average streamflows the Shoalhaven scheme is used to transfer what are essentially run-of-river flows from Lake Yarrunga to the Nepean and Warragamba reservoirs to supplement the yield of those catchments. The pump mark is the storage level (expressed as percentage of the Warragamba storage) at which pumping from the Shoalhaven storage would commence. In this study, a second pump mark based on Avon storage was added to the operating policy. This was introduced to avoid the possibility of water shortages in the Illawarra zone when Warragamba had an adequate storage.

\subsection{Scope for Optimizing Operating Rules}

[24] System drought security (as measured by the probability of experiencing restrictions at each of the four levels) is most affected by the selection of restriction trigger levels and the Shoalhaven and Avon pump marks. The selection of restriction levels is particularly important. As the trigger level for level 1 restrictions is lowered, the chance of entering restrictions is reduced at the expense of a greater risk of experiencing level 4 restrictions or even running out of water during a severe drought.

[25] The selection of appropriate pump marks is also important. Selection of high pump marks is likely to result in a greater chance of reservoir spillage and hence expensive wastage of pumped Shoalhaven water. Selection of low pump marks may severely impact on drought security; by the time the system draws down to a low pump mark, the unregulated river flow in the Shoalhaven may be too low to adequately augment Warragamba and Avon reservoirs. The selection of an appropriate pump mark necessitates a careful trade-off between drought security and pumping costs. 
Moreover, as water consumption increases due to population growth, the pump marks may have to be raised to maintain drought security.

[26] The drawdown curves have already been tuned to minimize spill from the system. In addition, the NetLP in the WATHNET optimizes water assignments within the network and in doing so further optimizes the distribution of stored water within the system. From this point of view, it was judged that the current drawdown curves do not warrant further optimization in this study.

\section{Optimization Model}

[27] This section first describes the decision variables and the objective function used in the case study, and then the parallel GA model is briefly outlined.

\subsection{Decision Variables}

[28] Eight decision variables require optimization. Decision(1) to decision(4) represent the four storage levels which trigger different levels of outdoor water restrictions. To avoid infeasible decisions the four trigger levels need to form a decreasing sequence, which can be obtained using the following mapping:

$$
\begin{aligned}
\operatorname{level}(j)= & \operatorname{level}(j+1)+[100-\operatorname{level}(j+1)] \\
& \times \operatorname{decision}(j), j=4, . ., 1
\end{aligned}
$$

where level(5) is an additional level set to $10 \%$ to ensure that the minimum trigger level never falls below $10 \%$ of Warragamba storage. This constrains the search space by eliminating solutions that a priori are judged unacceptable.

[29] Decision(5) and decision(6) represent the pump marks for Warragamba and Avon respectively below which pumping from Shoalhaven will commence to supply the two demand zones: Sydney and Illawarra. They are constrained to lie between 25 and $99 \%$.

[30] Decision(7) is the trigger storage volume in Warragamba below which construction of the desalination plant commences. Decision(8) is the capacity of the desalination plant. The trigger level for the desalination plant is, by constraint, lower than the lowest trigger level for outdoor water restrictions in order that the desalination plant be the last option chosen for supplying water. The desalination option is implemented as follows. If during a replicate, the Warragamba storage level falls below the desalination trigger level, construction of the desalination plant commences. After 12 months the plant will be ready to provide water for the reminder of the replicate.

\subsection{Objective Function}

[31] The objective of the optimization problem is to minimize the expected annual operating cost to meet demand corresponding to a particular population scenario. For a given set of decision variables proposed by the GA, the WATHNET simulation model performs Monte Carlo analysis to evaluate the following objective function:

$$
\begin{aligned}
\text { objF } & =C_{F}+\exp \text { Cost } \\
& =C_{F}+\frac{1}{N M} \sum_{i=1}^{M} \sum_{t=1}^{N}\left[C_{P}(i, t)+C_{D}(i, t)+C_{C}(i, t)+C_{R}(i, t)\right]
\end{aligned}
$$

where expCost is the expected annual operating cost, $t$ represents the simulation year ranging from 1 to $N, i$ is the replicate number ranging from 1 to $M$.

[32] To evaluate (2), WATHNET requires access to two data files. The first file contains the streamflow and climate data for the $\mathrm{M}$ N-year replicates at monthly resolution. Such a file is created by the program WATSTRM which calibrates a multisite AR(1) model to annual historic streamflow and climate data using the EM algorithm [Kuczera, 1987] and then stochastically generates annual times series at each site which are then disaggregated using a simple nonparametric method called the method of fragments. The second file contains demand data. Using the generated climate data saved in the first file, a demand file is created for a selected population scenario year; this ensures the correlation between low rain days and high outdoor domestic consumption is preserved. WATHNET evaluates the objective function by converting the decision variables proposed by the GA into operating rules which are used to guide the simulation for each N-year replicate. The objective function in (2) has five components.

[33] $C_{P}$ is the cost of pumping from the Shoalhaven system, which includes the cost of pumping for water supply to the Sydney and Illawarra zones. Pumping from the Shoalhaven involves a $612 \mathrm{~m}$ lift assumed to cost \$20/ML.

[34] $C_{D}$ is the cost of building a desalination plant and producing water once the plant is commissioned. Linstrum et al.'s [2000] indicative costs were adopted as follows: (1) The cost of commissioning a new desalination plant is \$2 million per ML installed daily capacity with a limit on installed capacity of $500 \mathrm{ML} /$ day. (2) The total operating cost of producing desalinated water from the plant is $\$ 2000 /$ ML.

[35] $C_{C}$ is the cost of rationing commercial and/or residential indoor water use during a severe drought. The actual estimation of the economic losses represents a major undertaking. In this study, a conservative yet reasonable approach is adopted. The economic loss due to restricting commercial water was assumed to be proportional to the degree of rationing with the constant of proportionality being the gross domestic product (GDP) of the Sydney region. This loss arises from closure of commercial activities due to lack of water for sanitary or process purposes. The estimation of economic loss due to domestic indoor water restrictions presents a difficult problem. To acknowledge the seriousness of such rationing the value judgment is made that the penalty for indoor restrictions should be equal to the economic loss associated with restriction of commercial use. It is important to stress that rationing of indoor or commercial usage only occurs when the headworks system physically runs out of water.

[36] $C_{F}$ is a penalty imposed if system reliability drops below 90\%. This constraint has been imposed to ensure that the GA in pursuit of a minimum economic loss does not produce solutions, which are deemed socially and politically unacceptable. If more than $10 \%$ of simulation years experience water shortages, the solution is considered unsatisfactory and is therefore penalized. The penalty $C_{F}$ is added to the 
expected cost expCost using the following multiplicative scheme:

$C_{F}= \begin{cases}10 \times \exp \operatorname{Cost} \times\left(\frac{90-\text { reliability }}{10}\right) & \text { if reliability }<90 \% \\ 0 & \text { otherwise }\end{cases}$

where reliability is derived by calculating the probability of experiencing restrictions in any year during the Monte Carlo simulation. This allows the GA to explore decisions that violate the minimum system reliability with the disincentive of a steeply increasing penalty as reliability drops below $90 \%$. For example, if reliability equaled $80 \%$, the solution would be penalized by setting $C_{F}$ equal to 10 times the annual expected operating cost expCost.

[37] $C_{R}$ is the cost of imposing restrictions on outdoor water use. Dandy [1992] argued that the theory of consumer willingness to pay for water could be used to evaluate the economic impact of restrictions on outdoor domestic water consumption. Following Dandy, suppose a water authority supplies water at a price of $\mathrm{p}_{1}(\$ / \mathrm{kL})$ with no limit on the allowable consumption by an individual household. A demand curve for a particular household is illustrated in Figure 2. During a drought, suppose the authority imposes restrictions forcing consumers to reduce consumption from $\mathrm{q}_{1}$ to $\mathrm{q}_{2}$ with a shadow price of $\mathrm{p}_{2}$. The net loss of benefits to the consumer and authority is the sum of the loss of consumer surplus (area xba in Figure 2) and the loss of revenue to the authority $\left(\right.$ area $\mathrm{xaq}_{1} \mathrm{q}_{2}$ ) yielding a total loss defined by area $\mathrm{baq}_{1} \mathrm{q}_{2}$.

[38] A price-demand relationship with constant elasticity $\varepsilon(\varepsilon \neq-1)$ was assumed to apply over most of the demand range. This yields a hyperbolic price-demand curve for which price $\rightarrow \infty$ as demand $\rightarrow 0$. Therefore a maximum price $p_{*}$ is imposed with $p_{*}$ being the price at which a substitute supply of water would be sought. The total loss of economic benefits due to water restrictions can be shown to be

$$
\begin{aligned}
\mathrm{C}_{\mathrm{R}} & =\int_{\mathrm{q}_{2}}^{\mathrm{q}_{1}} \mathrm{pdq} \\
& = \begin{cases}\frac{\varepsilon}{1+\varepsilon} \mathrm{p}_{1} \mathrm{q}_{1}\left[1-\left(\frac{\mathrm{q}_{2}}{\mathrm{q}_{1}}\right)^{1+\frac{1}{\varepsilon}}\right] & \text { if } \mathrm{q}_{2}>\mathrm{q}_{*} \\
\frac{\varepsilon}{1+\varepsilon} \mathrm{p}_{1} \mathrm{q}_{1}\left[1-\left(\frac{\mathrm{q}_{*}}{\mathrm{q}_{1}}\right)^{1+\frac{1}{\varepsilon}}+\mathrm{p}\left(\mathrm{q}_{*}-\mathrm{q}_{2}\right)\right] & \text { otherwise }\end{cases}
\end{aligned}
$$

The following values were considered indicative for the Sydney case study: $\mathrm{p}_{1}=\$ 0.6 / \mathrm{kL}, \varepsilon=-0.25$, and $\mathrm{p}_{*}=$ $\$ 1.20 / \mathrm{kL}$.

\subsection{Parallel GA Model}

[39] The GA formulation used in this case study was described by Cui and Kuczera [2003]. With regard to its implementation and performance in a parallel computing environment, readers are referred to Cui [2004] for detailed description.

[40] The parallel virtual machine (PVM) is a tool for passing messages between processors in a cluster [Geist et

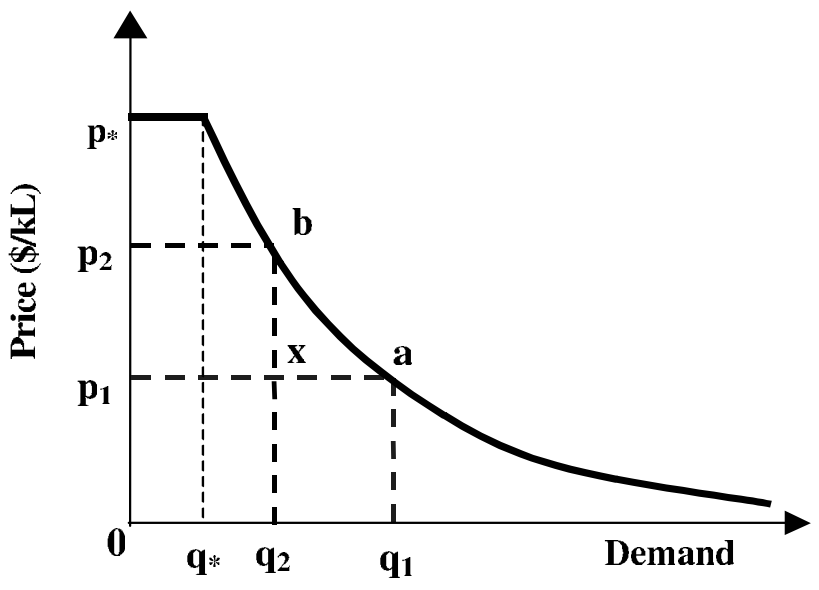

Figure 2. Household demand-price relationship showing loss of revenue $\left(\right.$ area $\mathrm{xaq}_{1} \mathrm{q}_{2}$ ) and consumer surplus (area $\mathrm{xba}$ ) due to imposition of restrictions.

al., 1994]. A traditional parallel programming paradigm, the master-slave approach, was adopted in this study to perform the parallel computations. The master program is responsible for process spawning, initialization, and data collection and reporting of results. The slave programs located on different processors perform the actual Monte Carlo simulations.

[41] The general framework for parallel implementation of the GA using the master-slave protocol is as follows.

[42] 1. Master program generates initial population of decision vectors.

[43] 2. Master sends decision vectors to idle slave processors using PVM protocol. If there are no decision vectors to be evaluated, go to step 5 .

[44] 3. Slave processor evaluates the objective function using WATHNET model and sends result as a message to the master.

[45] 4. Master receives objective function value from the slave and goes to step 2 .

[46] 5. Master implements elitist strategy to preserve the best solutions.

[47] 6. If stopping criteria are not met, master starts new generation by producing a new population using GA operators (tournament, crossover, mutation, and inversion) and goes to step 2 .

[48] 7. Master terminates GA if stopping criteria are satisfied.

[49] After the initial population of decision vectors, each consisting of 8 decisions, is generated, PVM routines are employed to send the decision variables to idle slave processors to evaluate the objective function using WATHNET. The master then waits for an objective function value from a slave processor. When it receives a result from a slave, the master assigns a new decision vector to the idle slave until all the decision vectors of the current generation have been evaluated. When the results for the whole population have been received, the master implements the population selection strategy (elitism) to finalize the composition of the population for the current generation. If the stopping criteria are not satisfied, the master will commence the next GA generation. It produces the next generation of decision variables using the genetic operators, tournament 


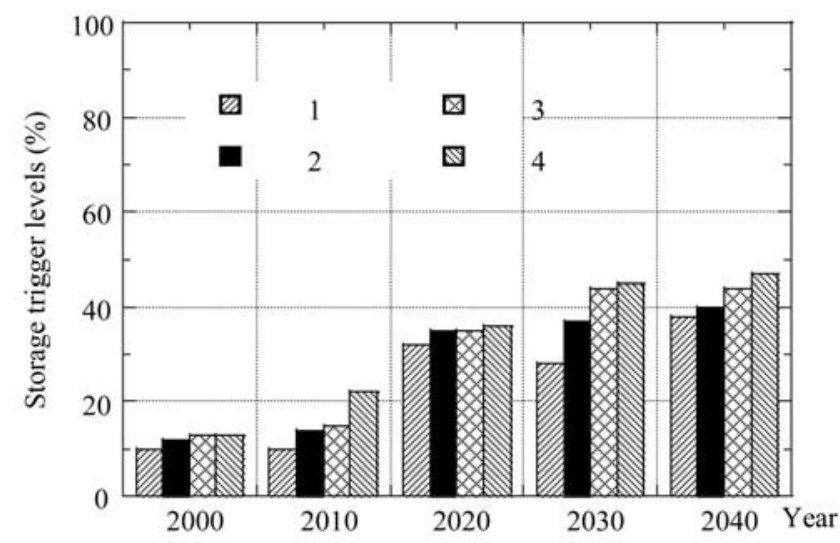

Figure 3. Near-optimal restriction trigger levels for different scenario years. See color version of this figure in the HTML.

selection, crossover, mutation and inversion. The whole process is repeated until the stopping criteria are met.

\section{Results and Discussion}

\subsection{Data Inputs}

[50] The system was optimized using a cluster of processors supervised by PVM. The cluster is an Athlon-based system consisting of 10 available nodes interconnected via an Intel 460T 24 port 10/100 switch. The GA parameters suggested by Cui and Kuczera [2003] were used as default values for this case study: crossover rate $=0.9$; mutation rate $=1 /$ (population size $)$; inversion rate $=0.7$; and population size $=70$. The search stops if the best solution does not improve for 6 generations.

[51] The objective function (2) is evaluated by performing a WATHNET simulation using up to 10,000 50-year replicates of future streamflow, climate and demand at a monthly resolution. The case study compares results for different demand scenarios corresponding to the population expected in the years 2000,2010,2020, 2030 and 2040 and for simulations with different numbers of replicates.

\subsection{Results for 1000 Replicate Simulations}

[52] This section reports on the results of optimizing the headworks operating rules using 1000 replicates of streamflow and demand to account for climate variability.

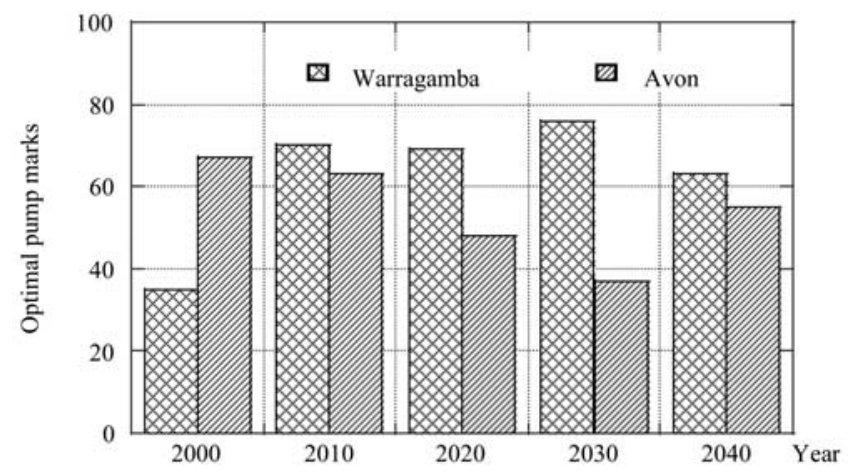

Figure 4. Pump marks for Warragamba and Avon reservoirs for different scenario years. See color version of this figure in the HTML.
Table 1. Near-Optimal Desalination Results

\begin{tabular}{lllccc}
\hline & \multicolumn{5}{c}{ Population Scenario Year } \\
\cline { 2 - 6 } \multicolumn{1}{c}{ Decision } & 2000 & 2010 & 2020 & 2030 & 2040 \\
\hline Trigger level, ${ }^{\text {a }} \%$ & 1 & 3 & 26 & 16 & 23 \\
Capacity, ML/d & 358 & 95 & 92 & 280 & 494 \\
\hline
\end{tabular}

${ }^{\text {a }}$ The trigger level is defined as a percentage of the capacity of Warragamba reservoir.

[53] Figure 3 presents the near-optimal restriction trigger levels. The general trend is that the restriction trigger levels increase with increase in water demand arising from population growth. Of note is the unexpectedly small spacing between level 1 and level 4 trigger levels, a point addressed below.

[54] Figure 4 presents the near-optimal pump marks for Warragamba and Avon as function of scenario year. Both pump marks show no consistent trend with values largely contained in the range $40 \%$ to $70 \%$.

[55] Table 1 presents the results for the desalination option. The trigger level for constructing the desalination plant is, by constraint, lower than the lowest trigger level for outdoor water restrictions in order that the desalination plant be the last option for supplying water. This result will be discussed later in this section.

[56] Table 2 presents a breakdown of the objective function components for each population scenario year. Rows 1 and 2 report the penalties of imposing restrictions on outdoor and commercial/indoor water use. Rows 3 and 4 report the expected costs of pumping triggered by the Warragamba and Avon pump marks. Row 5 reports the expected cost of constructing the desalination plant and row 6 presents the expected cost of producing water from the desalination plant. Row 7 is the penalty of not meeting the minimum system reliability of $90 \%$. The last row reports the total expected penalty for each population scenario year. It is noted that the trend for each penalty is to increase with water demand. Of significance here is the rapid increase in the penalty due to imposing outdoor water restrictions. For year 2000 there is no penalty incurred for constructing the desalination plant and utilizing its water; this means the desalination plant was never commissioned. However, for the year 2010 onward, the desalination plant is commissioned in some replicates with increasing capacity, yet desalination water production remains very small. It is also noted that no penalty is incurred for failure to satisfy the minimum reliability of $90 \%$ for all scenario years.

[57] To interpret the results, it is necessary to present indicative unit costs $(\$ / \mathrm{ML})$ associated with the various strategies to supply water or reduce demand. Pumping from the Shoalhaven system represents the cheapest option; it is approximately $\$ 20 / \mathrm{ML}$. Imposition of restrictions on outdoor domestic demand imposes a penalty of the order of $\$ 100 / \mathrm{ML}$, whereas rationing commercial or indoor water imposes a penalty of $\$ 250000 / \mathrm{ML}$. The desalination plant has a capital cost of $\$ 2,000,000$ per ML/day installed capacity and a production cost of $\$ 2000 / \mathrm{ML}$. Seen in this light the rationing of commercial or indoor demand or introduction of desalination are seen by the GA as options of last resort. 
Table 2. Objective Function Component Penalties for Optimizing Eight Decision Variables ${ }^{\mathrm{a}}$

\begin{tabular}{llllll}
\hline & \multicolumn{5}{c}{ Population Scenario Year } \\
\cline { 2 - 6 } \multicolumn{1}{c}{ Objective Function Component } & 2000 & 2010 & 2020 & 2030 & 2040 \\
\hline Restriction: outdoor (1) & 28.2 & 105.7 & 801.3 & 2003.6 & 3256.0 \\
Restriction: commercial + indoor (2) & 0.0 & 0.8 & 8.5 & 15.0 & 21.4 \\
Pump mark: Warragamba (3) & 1128.8 & 1090.5 & 1053.8 & 1021.8 & 1000.0 \\
Pump mark: Avon (4) & 78.0 & 132.0 & 193.4 & 253.5 & 297.6 \\
Desalination: construction (5) & 0.0 & 2.0 & 3.7 & 11.2 & 19.8 \\
Desalination: production (6) & 0.0 & 1.2 & 1.9 & 4.1 & 5.5 \\
Reliability constraint penalty (7) & 0.0 & 0.0 & 0.0 & 0.0 & 0.0 \\
Total penalty (8) & 1235.0 & 1408.3 & 2062.6 & 3309.2 & 4600.3 \\
\hline
\end{tabular}

${ }^{\mathrm{a}}$ Values in $\$ 1000 /$ year.

[58] Returning to Table 2, it is noted that when demand is low the system experiences little drought stress. The GA therefore adopted the strategy of setting restriction trigger levels close to the minimum allowed value of $10 \%$ to avoid the imposition of outdoor restrictions which incur penalties of about \$100/ML; indeed, outdoor restrictions account for only $2.3 \%$ and $7.5 \%$ of the total expected cost in the years 2000 and 2010 while total pumping accounts for $97.7 \%$ and $86.8 \%$ of the total penalty. During a drought, the rate of drawdown can be reduced by pumping from the Shoalhaven and/or imposing outdoor restrictions. Because pumping from the Shoalhaven was cheaper than imposing restrictions the GA set the pump marks well above the first restriction trigger level to ensure that pumping was the first strategy used to reduce the drawdown rate.

[59] As demand grows the almost exclusive reliance on pumping is no longer possible. Whereas the pump marks largely remain in the 40 to $70 \%$ range for the scenario years 2010 to 2040, the level 1 restriction trigger level climbs from $10 \%$ in 2000 to about $38 \%$ in 2040 . While the GA has maintained its strategy of first pumping from the Shoalhaven it has to impose outdoor restrictions earlier in the drawdown phase to avoid punitive penalties arising from rationing commercial/indoor domestic demand or desalination. By the year 2040 outdoor restrictions represent $71 \%$ of total penalty whereas pumping has fallen to $28 \%$.

[60] Of interest is the observation that as demand grows by $27 \%$ from 2000 to 2040 the pump marks do not display any consistent tendency to increase with demand. This can be understood by noting that as the pump mark increases the air space in the reservoirs available to store a large unregulated inflow is reduced. This increases the chance of a spill from the reservoir. In the case of Avon and Warragamba reservoirs, spills are lost to the system. Therefore, as the pump mark is increased more of the pumped water is 'in effect' being wastefully pumped over the spillway. It is for this reason that the GA has opted to limit the pump marks and hence the amount of pumping.

[61] Figure 3 reveals a seemingly unexpected result; the difference between level 1 and level 4 storage trigger values is small implying the GA seeks to impose the severest level of outdoor restrictions (i.e., a complete ban on outdoor domestic use) soon after commencing restrictions. While this is not typical of Australian practice this strategy minimizes the drawdown rate and hence minimizes the risk of imposing punitive rationing or building a desalination plant.

[62] Table 2 shows that the desalination option is largely avoided by the GA. Even in 2040 the desalination option accounts for only $0.5 \%$ of the total expected penalty. The insensitivity of the total expected penalty to the desalination options is the primary reason for the variability in the desalination options reported in Table 1. For scenario year 2000 desalination was never implemented by the GA because the storage never fell below the $1 \%$ trigger level in any of the replicates. As a result, the plant capacity of $358 \mathrm{ML} /$ day is arbitrary; the plant was never commissioned.

[63] In summary, although it cannot be demonstrated that the GA found optimal results, it is suggested that the GA results are nonetheless consistent with the strategy that minimizes total expected costs. In particular, the GA clearly opted for a strategy that favored use of lowest cost water and steered away from rules that increased the risk of rationing commercial and indoor domestic demand and exercising the desalination option.

\subsection{Results for More Replicates}

[64] The results reported so far were based on 50-year simulations using 1000 replicates of future streamflow and

Table 3. Decision Variables Obtained From the GA for Each Replicate Run and Population Scenario Year

\begin{tabular}{|c|c|c|c|c|c|c|c|c|c|}
\hline \multirow[b]{2}{*}{ Year } & \multirow[b]{2}{*}{ Number of Replicates } & \multicolumn{4}{|c|}{ Restriction Storage Trigger Levels, \% } & \multicolumn{2}{|c|}{ Pump Marks, \% } & \multicolumn{2}{|c|}{ Desalination } \\
\hline & & Level 1 & Level 2 & Level 3 & Level 4 & Warragamba & Avon & Storage Trigger Level, \% & Capacity, ML/d \\
\hline 2000 & 2000 & 14 & 11 & 10 & 10 & 52 & 55 & 0 & 331 \\
\hline 2000 & 10000 & 13 & 11 & 10 & 10 & 74 & 56 & 8 & 264 \\
\hline 2010 & 2000 & 16 & 15 & 14 & 10 & 69 & 92 & 0 & 442 \\
\hline 2010 & 10000 & 14 & 12 & 12 & 12 & 55 & 53 & 11 & 204 \\
\hline 2020 & 2000 & 37 & 36 & 32 & 31 & 34 & 25 & 2 & 47 \\
\hline 2020 & 10000 & 39 & 34 & 32 & 31 & 64 & 69 & 24 & 85 \\
\hline 2030 & 2000 & 49 & 48 & 45 & 41 & 76 & 75 & 15 & 360 \\
\hline 2030 & 10000 & 42 & 41 & 38 & 38 & 81 & 43 & 26 & 77 \\
\hline 2040 & 2000 & 46 & 44 & 43 & 42 & 77 & 39 & 20 & 151 \\
\hline 2040 & 10000 & 45 & 42 & 41 & 41 & 88 & 27 & 20 & 4 \\
\hline
\end{tabular}


Table 4. Total Penalty Value for Each Replicate Run and Population Scenario Year ${ }^{\mathrm{a}}$

\begin{tabular}{llllll}
\hline & \multicolumn{5}{c}{ Population Scenario Year } \\
\cline { 2 - 6 } Replicates & 2000 & 2010 & 2020 & 2030 & 2040 \\
\hline 1000 & 1235 & 1408 & 2062 & 3309 & 4600 \\
2000 & 1228 & 1336 & 2044 & 3148 & 4655 \\
10,000 & 1223 & 1329 & 2031 & 3121 & 4570 \\
\hline
\end{tabular}

${ }^{\mathrm{a}}$ Values in $\$ 1000 / \mathrm{ML}$.

climate-related demand. The question arises, how does the number of replicates affect the exposure to severe droughts. If too few replicates are used the GA may opt for decisions that render the system vulnerable to running out of water in a severe drought. To appreciate the influence of the number of replicates this section examines GA results produced using 2000 and 10000 replicates.

[65] Table 3 shows the decision variables obtained from the GA for each scenario year and replicate run. Tables 4, 5, and 6 present respectively the total expected penalty, the standard errors and the $95 \%$ confidence limits on the total expected penalty for each scenario year and replicate run.

[66] Table 3 reveals that the four restriction trigger levels are overall consistent regardless of the replicate run for each population scenario year. Compared to the pump marks for Warragamba, the Avon pump mark exhibits more variability for a given population scenario year. This is attributed to the fact that the Warragamba pumping cost dominates overall pumping cost; this is to be expected as Avon reservoir only serves $10 \%$ of the population. The desalination decisions show considerable variability. This is to be expected given that desalination minimally contributes to the total penalty.

[67] Table 4 reveals not unexpectedly that the total penalty exhibits variability between replicate runs. To gauge whether the differences are due to sampling error or due to the GA converging to a different solution it is necessary to consider the standard errors (SE) and the $95 \%$ confidence limits. For large samples, the SE should be inversely proportional to the square root of the number of replicates. Table 5 confirms this relationship for all replicate runs demonstrating that SE decreases as the number of replicates increases. Table 6 demonstrates that the confidence intervals overlap indicating that the GA results are consistent over the different replicate runs. Clearly the 10,000-replicate runs produce the most accurate penalties, but they are computationally expensive. The results suggest that the 1000 50-year replicate runs produce decisions, which are largely consistent with the 1000050 -year replicate runs.

\section{Conclusions}

[68] In this study, the Sydney headworks system was used as a case study to investigate the key aspects of a full-scale

Table 5. Standard Error of Total Expected Penalty for Each Replicate Run and Population Scenario Year ${ }^{\mathrm{a}}$

\begin{tabular}{llllll}
\hline & \multicolumn{5}{c}{ Population Scenario Year } \\
\cline { 2 - 6 } Replicates & 2000 & 2010 & 2020 & 2030 & 2040 \\
\hline 1000 & 10.0 & 58.6 & 68.1 & 105.3 & 138.5 \\
2000 & 6.1 & 20.3 & 45.7 & 86.9 & 98.4 \\
10,000 & 2.3 & 3.4 & 19.6 & 31.5 & 42.9 \\
\hline
\end{tabular}

${ }^{\mathrm{a}}$ Values in $\$ 1000 / \mathrm{ML}$.
Table 6. The $95 \%$ Confidence Interval on the Total Expected Penalty

\begin{tabular}{cccc}
\hline & \multicolumn{3}{c}{ Replicates } \\
\cline { 2 - 4 } Scenario Year & 1000 & 2000 & 10,000 \\
\hline 2000 & $1215-1255$ & $1216-1246$ & $1206-1228$ \\
2010 & $1291-1526$ & $1296-1377$ & $1323-1336$ \\
2020 & $1926-2198$ & $1952-2135$ & $1992-2070$ \\
2030 & $3098-3519$ & $2975-3322$ & $3058-3184$ \\
2040 & $4323-4877$ & $4458-4851$ & $4484-4656$ \\
\hline
\end{tabular}

headworks optimization using parallel GA. The eight decision variables, affecting restrictions, interbasin transfers and desalination, were optimized for five different population scenario years 2000, 2010, 2020, 2030 and 2040.

[69] Although it cannot be established that the GA converged to a true optimum, the soundness of the nearoptimal solutions can be assessed by considering the unit costs associated with each operating strategy. The GA yielded solutions that were consistent with this ranking. It was found that the restriction trigger levels increased with growing water demand while the pump marks largely operated in the range 40 to $70 \%$. When the demand was low, the objective function was dominated by pumping with the chance of outdoor restrictions minimized by very low restriction trigger levels. However, the restriction storage trigger levels gradually increased with increasing water demand. For year 2040, more than half of the total penalty was due to imposition of outdoor water restrictions even though the expected cost of pumping increased when compared to year 2000. At high levels of demand, the GA largely avoided the expensive desalination option choosing to impose high restriction trigger levels and pump marks. Overall the GA results were judged consistent with the strategy that minimizes expected annual costs.

[70] The sensitivity of the optimized results to the number of 50-year replicates was investigated. The 10,000-replicate runs produce the most accurate penalties, but they are computationally expensive. Comparison of results for 1000, 2000 and 10000 replicates revealed overall consistency in penalties. Likewise the GA decisions were largely consistent with decisions associated with the smallest contributions to the total penalty showing greatest variations.

[71] In conclusion, the case study demonstrated the ability of parallel GA to identify what can be argued to be near-optimal solutions for a complex system subjected to stochastic inputs. It has also highlighted issues with regard to the number of replicates used in the Monte Carlo simulation.

[72] Acknowledgments. The Sydney Catchment Authority is thanked for providing information about the headworks system. The authors bear sole responsibility for the case study. The helpful comments of the two anonymous reviewers are acknowledged.

\section{References}

Crawley, P. D., and G. C. Dandy (1993), Optimal operation of multiplereservoir system, J. Water Resour. Plann. Manage., 119(1), 1-17.

Cui, L. J. (2004), Optimization of urban water supply headworks systems using probabilistic search methods and parallel computing, Ph.D. thesis, Univ. of Newcastle, Newcastle, New South Wales, Australia.

Cui, L. J., and G. Kuczera (2003), Optimization of urban water supply headworks using probabilistic search methods, J. Water Resour. Plann. Manage., 129(5), 380-387. 
Dandy, G. C. (1987), Water resource systems analysis, paper presented at National Workshop on Water Research, Dep. of Primary Ind. and Energy, Canberra, Aug.

Dandy, G. C. (1992), Assessing the economic cost of restrictions on outdoor water use, Water Resour. Res., 28(7), 1759-1766.

Department of Water Resources (1995), IQQM: Integrated water quantity and quality model, Rep. TS95.019, Sydney, New South Wales, Australia.

Geist, A., A. Beguelin, J. Dongarra, W. Jiang, R. Manchek, and V. Sunderam (1994), PVM: Parallel virtual machine-A users' guide and tutorial for networked parallel computing, Tech. Rep. ORNL/TM-12187, Mass. Inst. of Technol., Cambridge.

Goldberg, D. E. (1989), Genetic Algorithms in Search, Optimization and Machine Learning, Addison-Wesley, Boston, Mass.

Kuczera, G. (1987), On maximum likelihood estimators for the multi-site lag-one streamflow model: Complete- and incomplete-data cases, Water Resour. Res., 23(4), 641-645.

Kuczera, G. (1997), WATHNET-Generalized water supply headworks simulation using network linear programming, version 3, software, Sch. of Eng., Univ. of Newcastle, Newcastle, New South Wales, Australia.
Kuczera, G., and G. A. Diment (1987), A general water supply simulation model WASP, J. Water Resour. Plann. Manage., 114(4), 365-382.

Linstrum, A., G. Crisp, and G. Hughes (2000), Desalination in Western Australia-Sn overview, paper presented at Hydro 2000 Interactive Hydrology: 3rd International Hydrology and Water Resources Symposium, Inst. of Eng., Perth, Western Australia, Australia.

Snowy Mountains Engineering Corporation (1996), Sydney water supply strategy review phase II: Water resources investigation, Rep. SMEC 31311, Cooma, New South Wales, Australia.

Wang, Q. J. (1991), The genetic algorithms and its application to calibrating conceptual rainfall-runoff models, Water Resour. Res., 27(9), 24672471 .

Wardlaw, R., and M. Sharif (1999), Evaluation of genetic algorithms for optimal reservoir system operation, J. Water Resour. Plann. Manage., $125(1), 25-33$.

L. Cui and G. Kuczera, School of Engineering, University of Newcastle, Callaghan, NSW 2308, Australia. (lijie.cui@newcastle.edu.au) 